\title{
On fundamental group of soft topological spaces
}

\author{
Ali Akbar Bahredar ${ }^{1}$, Nader Kouhestani ${ }^{1}$, and Hadi Passandideh ${ }^{1}$ \\ ${ }^{1}$ University of Sistan and Baluchestan
}

July 30, 2020

\begin{abstract}
In this paper we introduce the notion of fundamental group for soft topological spaces. To do so, we define soft paths, soft loops and the notion of $\xi$-soft path homotopy, and study some of their basic properties. We also show that the fundamental group of an $\varepsilon$-soft topological group is commutative, and that $\pi_{1}^{\text {soft }}$ is a functor between the category of soft topological spaces and the category of groups.
\end{abstract}

\section{Hosted file}

softhomotopy2.pdf available at https://authorea.com/users/347566/articles/473213-onfundamental-group-of-soft-topological-spaces 